Review

\title{
Sodium Iodide Symporter for Nuclear Molecular Imaging and Gene Ther- apy: From Bedside to Bench and Back
}

\author{
Byeong-Cheol Ahn ${ }^{\bowtie}$
}

Department of Nuclear Medicine, Kyungpook National University School of Medicine and Hospital, Daegu, South Korea

Corresponding author: Byeong-Cheol Ahn, MD, PhD, Professor and Director, Department of Nuclear Medicine, Kyungpook National University School of Medicine and Hospital, 50 Samduck 2-Ga, Jung Gu, Daegu, South Korea $700-412$. Tel: 82-53-420-5583; Fax: 82-53-422-0864; E-mail: abc2000@knu.ac.kr

(C) Ivyspring International Publisher. This is an open-access article distributed under the terms of the Creative Commons License (http://creativecommons.org/ licenses/by-nc-nd/3.0/). Reproduction is permitted for personal, noncommercial use, provided that the article is in whole, unmodified, and properly cited.

Received: 2011.10.28; Accepted: 2012.01.23; Published: 2012.04.11

\begin{abstract}
Molecular imaging, defined as the visual representation, characterization and quantification of biological processes at the cellular and subcellular levels within intact living organisms, can be obtained by various imaging technologies, including nuclear imaging methods. Imaging of normal thyroid tissue and differentiated thyroid cancer, and treatment of thyroid cancer with radioiodine rely on the expression of the sodium iodide symporter (NIS) in these cells. NIS is an intrinsic membrane protein with 13 transmembrane domains and it takes up iodide into the cytosol from the extracellular fluid. By transferring NIS function to various cells via gene transfer, the cells can be visualized with gamma or positron emitting radioisotopes such as Tc-99m, I-I23, I-I3I, I-I 24 and F-I 8 tetrafluoroborate, which are accumulated by NIS. They can also be treated with beta- or alpha-emitting radionuclides, such as I-I3I, Re- I86, Re-I88 and At-2II, which are also accumulated by NIS. This article demonstrates the diagnostic and therapeutic applications of NIS as a radionuclide-based reporter gene for trafficking cells and a therapeutic gene for treating cancers.
\end{abstract}

Key words: sodium iodide symporter, molecular imaging, radionuclide-based imaging, gene therapy, radionuclide.

\section{Introduction}

The ability of the thyroid gland to concentrate iodide has long provided the basis for diagnosis and therapeutic management of benign thyroid diseases and thyroid cancer [1]. Thyroid scintigraphy with radioiodines or technetium-99m (Tc-99m) pertechnetate has played a key role in the evaluation of thyroid nodules with its ability of providing anatomical and functional information since the advent of modern endocrinology [2]. Radioiodine via an 'atomic cocktail' was first used medically for thyroid cancer treatment under the Atomic Energy Act since 1946 [3]. Thereafter, millions of patients with benign or malignant thyroid diseases have been given radioiodine for di- agnostic and therapeutic purposes with successful outcomes. However, the uptake mechanism of radioiodine into thyroid tissue or thyroid cancers was not fully elucidated until 1996, when the sodium iodide symporter (NIS) was finally cloned [4]. This not only improved understanding of thyroid pathophysiology tremendously, but also offered promising molecular biological strategies of imaging and treatment. Clinical theranostic application of NIS function using radioiodine was projected to biologic preclinical experimental studies after the NIS cloning. NIS expression can be imaged feasibly with simple radiotracers, such as radioiodines or Tc- $99 \mathrm{~m}$. By the easy imagina- 
ble characteristic of NIS, it has been used as an imaging reporter to monitor gene transfer.[5, 6] In addition to the potential as the imaging reporter gene, NIS has been used as a therapeutic gene to treat cancers through its ability to concentrate therapeutic doses of radionuclides in target cells [7-10].

This review is mainly focused on the theranostic application of NIS for radionuclide-based molecular imaging and radionuclide gene therapy in in vivo animal models.

\section{NIS}

NIS is an intrinsic plasma membrane glycoprotein with 13 transmembrane domains that actively mediates iodide transport into the thyroid follicular cells and several extrathyroidal tissues [11]. This protein plays an essential role in thyroid physiology by mediating iodide uptake into the thyroid follicular cells, a key step in thyroid hormone synthesis. NIS belongs to the sodium/solute symporter family or solute carrier family 5, which drives negatively-charged solutes into the cytoplasm using an electrochemical $\mathrm{Na}^{+}$gradient [12]. The symporter co-transports two sodium ions $\left(\mathrm{Na}^{+}\right)$along with one iodide $\left(\mathrm{I}^{-}\right)$, with the transmembrane sodium gradient serving as the driving force for iodide uptake; therefore, NIS functionality is dependent on the electrochemical sodium gradient that is maintained by the oubaine-sensitive $\mathrm{Na}^{+} / \mathrm{K}^{+}$ATPase pump (Fig. 1) [13].

NIS needs to be localized in the plasma membrane for efficient transportation of iodide into thyroid follicular cells. Poor iodide uptake in thyroid cancer cells compared to thyroid follicular cells is related to impaired targeting and retention of NIS at the membrane. Membrane localization of NIS requires thyroid stimulating hormone (TSH) stimulation; through TSH deprivation, NIS is not retained at the membrane, leading to a decrease in iodide uptake. Although TSH stimulation is essential for efficient NIS trafficking to plasma membrane of thyroid follicular cells, it is possible that TSH-independent mechanisms for the trafficking exist because non-thyroidal tissues also retain NIS at the membrane in the absence of TSH stimulation. One suggested mechanism of NIS targeting to the membrane is the phosphorylation of NIS at serine residues in the carboxy terminus. Protein-protein interaction is another suggested mechanism for the trafficking. NIS contains PDZ, dileucine and dipeptide motifs which might be associated with trafficking $[1,13]$. Non-thyroidal cancer tissues also can express NIS; however, only $20-25 \%$ of NIS-positive tumors showed iodide uptake partly due to the intracytoplasmic location of NIS [14].

Although expression of NIS is also detectable in normal extrathyroidal tissues such as the salivary glands, gastric mucosa and lactating mammary glands, the expression is not regulated by TSH and is present at lower levels in these tissues than in thyroid tissue. Iodide organification is a particular and unique characteristic of the thyroid gland, and long-term retention of iodide does not occur in the extrathyroidal tissues expressing NIS [15].

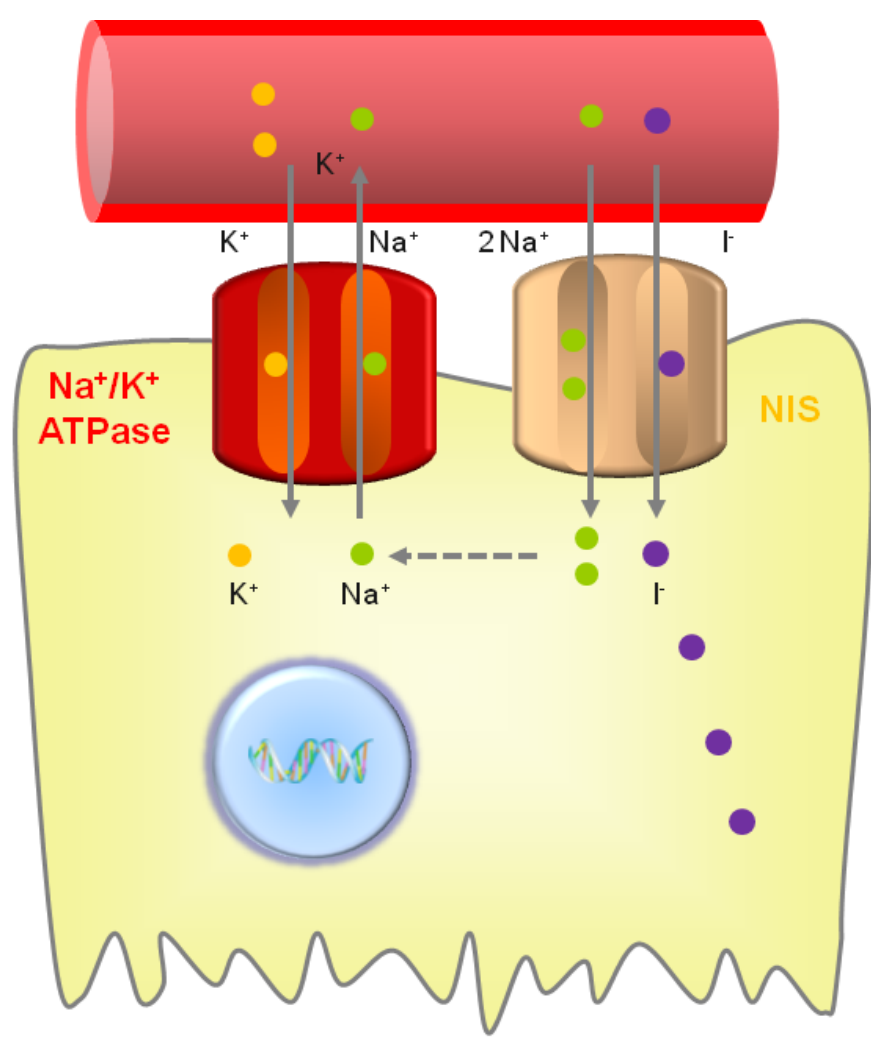

Figure I. lodide uptake function of NIS. NIS transports 2 sodium ions and I iodide ion into the cytoplasm together. The electrochemical sodium gradient generated by the oubaine-sensitive $\mathrm{Na}^{+} / \mathrm{K}^{+}$ATPase pump provides energy for this transfer.

\section{Radiopharmaceuticals for NIS}

NIS has marked advantages as an imaging reporter gene and as a therapeutic gene compared to other reporter or therapeutic genes due to the wide availability of radiopharmaceuticals and its well understood metabolism and clearance of these radiopharmaceuticals from the body [16].

NIS actively takes up radioiodine and Tc-99m; therefore, its function can be imaged with I-123, I-131, I-124 and Tc-99m [7, 15, 17]. No issues of labeling processes and stability arise when using these radiopharmaceuticals, whereas they may be a major concern of the radiolabeled ligands of other radionu- 
clide-based reporter genes, such as the dopamine D2 receptor or herpes simplex virus thymidine kinase (HSV-tk) genes [16].

I-123 is produced in a cyclotron by proton irradiation of enriched xenon-124 (Xe-124) in a capsule, decays by electron capture to tellurium-123 (Te-123) with a half-life of 13.2 hours, and emits gamma rays with predominant energies of $159 \mathrm{keV}$ (the gamma ray is primarily used for imaging) and $127 \mathrm{keV}$. I-123, mainly a gamma emitter, has a high counting rate compared with I-131 and provides a higher lesion-to-background signal, thereby improving sensitivity and imaging quality. Moreover, with the same administered activity, I-123 delivers an absorbed radiation dose that is approximately one-fifth that of I-131 to NIS-expressing tissues [18].

I-124 is a proton-rich isotope of iodine produced in a cyclotron by numerous nuclear reactions and decays to Te-124 with a half-life of 4.2 days. Its modes of decay are $74.4 \%$ electron capture and $25.6 \%$ positron emission. It emits gamma radiation with energies of 511 and $602 \mathrm{keV}$ [19].

I-131 is produced in a nuclear reactor by neutron bombardment of natural Te-127, decays by beta emission with a half-life of 8.0 days to Xe-133, and emits gamma rays as well. It most often ( $89 \%$ of the time) expends its $971 \mathrm{keV}$ of decay energy by transforming into the stable Xe-131 in two steps, with gamma decay following rapidly after beta decay. The primary emissions of I-131 decay are beta particles with a maximal energy of $606 \mathrm{keV}$ (89\% abundance, others, 248-807 $\mathrm{keV}$ ) and $364 \mathrm{keV}$ gamma rays (81\% abundance, others $723 \mathrm{keV}$ ) [19]. As I-131 emits both beta and gamma rays, it can be used to image NIS gene expression; however, it is not recommended for imaging due to poor image quality (by high energy of the gamma rays) and the high radiation burden (by the beta rays) compared to I-123.

Tc- $99 \mathrm{~m}$, a metastable nuclear isomer of Tc-99, has a half-life of 6.0 hours and emits $140 \mathrm{keV}$ gamma rays which is an optimal energy for scintigraphic imaging. Tc-99m, the most commonly used radionuclides in routine nuclear medicine imaging, is usually extracted from Tc-99m generators which contain parent nuclide molybdenum-99 (Mo-99) [2].

Recently, F-18 tetrafluoroborate (F-18 TFB) was developed as a positron-emitting radiopharmaceutical that is actively taken up by NIS [20]. The rapid uptake and efflux of F-18 TFB in the rat thyroid cell line parallels the behavior of Tc- $99 \mathrm{~m}$ pertechnetate, which is known to be taken up in cells expressing NIS [20]. Uptake of F-18 TFB to thyroid follicular cells is stimulated by TSH and blocked by perchlorate. It was suggested that F-18 TFB transport occurs with little or no coupling to sodium transport, or that TFB occupies a binding site on NIS but is transported very inefficiently.

I-131, rhenium-188 (Re-188), Re-186 and astatine-211 (At-211), which emit particles from their nuclei, are used for radionuclide therapy on cells expressing NIS $[1,8-10,13,21]$. Re-188 is an important therapeutic radionuclide, which is obtained on demand as a carrier-free sodium perrhenate by saline elution of the tungsten-188 (W-188)/ Re-188 generator system. With a half-life of 17.0 hours and emission of a high-energy beta ray (maximal energy of $2.12 \mathrm{MeV}$ ) and gamma ray $(155 \mathrm{keV}, 15 \%)$ for imaging, Re-188 offers the prospect of cost-effective preparation of radiopharmaceuticals for cancer treatment [22]. Cyclotron-driven neutron activator may be an alternative for on-demand supply of Re-188 [23].

Currently, At-211 is the most promising alpha-emitter that has been studied for cancer therapy. It is the heaviest halogen, with no stable isotope. It decays via a double-branch pathway with a mean alpha-energy of $6.7 \mathrm{MeV}(42 \% 5.9 \mathrm{MeV}$ and $58 \% 7.5$ $\mathrm{MeV}$ ) and a half-life of 7.2 hours. As a consequence of its electron capture branching to its daughter polonium-211, X-rays of 77 to $92 \mathrm{keV}$ in sufficient abundance are emitted, enabling external imaging (including single photon emission computed tomography [SPECT]) and gamma counting of blood samples as additional advantages. However, its widespread use in therapeutic doses is hindered as a result of limited availability of medium-energy cyclotrons with an alpha-particle beam for its production, which is currently feasible at only a few research centers [24]. Table 1 summarizes characteristics of radionuclides which can be used with NIS for diagnostic or therapeutic purposes.

\section{Use of NIS for diagnostic purposes in clinical nuclear medicine}

Gamma camera imaging with radioiodine (I-131 or I-123) can visualize metastatic lesions in differentiated thyroid cancer patients who have undergone total thyroidectomy because the lesions are highly efficient at trapping circulating iodine by expression of NIS (Fig. 2) [25]. Radioiodine scintigraphy, once the mainstay of post-therapy imaging surveillance, has largely been replaced by neck ultrasonography as the modality of choice for long-term imaging surveillance, although it still may be used for the detection of occult or distant metastases, particularly in the setting of a newly elevated serum thyroglobulin level [26]. Routine use of radioiodine scintigraphy for surveillance is not recommended for low-risk patients. However, it is still used in patients with intermediate 
or high risk of recurrence, as well as to assess patients for evidence of recurrence in the setting of an elevated thyroglobulin level with a negative neck ultrasonography. Scintigraphy performed after empiric treatment with high doses of I-131 is more sensitive than the usual diagnostic I-131 scanning [26].

I-124 positron emission tomography (PET) has higher sensitivity for the detection of thyroid cancer lesions with NIS expression compared with I-131 whole body scintigraphy due to lower background noise and the higher resolution of PET imaging than gamma camera imaging. Additionally, PET images can be fused with CT and/or magnetic resonance imaging [27].

Detection and localization of metastatic thyroid cancer lesions by radioiodine scintigraphy or PET rely on the expression of NIS in the cancer cells which accumulate radioiodine [27].

Table I. Radionuclides used for diagnostic or therapeutic purposes associated with NIS.

\begin{tabular}{|c|c|c|c|c|}
\hline radioisotopes & $\mathrm{T}_{1 / 2}$ & Emission & Most abundant energy & Medical use \\
\hline $\mathrm{I}-123$ & 13.2 hours & gamma ray & $159 \mathrm{keV}$ & Diagnostic imaging (Gamma camera) \\
\hline $\mathrm{I}-124$ & 4.2 days & $\begin{array}{l}\text { positron/gamma } \\
\text { ray }\end{array}$ & $511 \mathrm{keV} / 602 \mathrm{keV}$ & Diagnostic imaging (PET) \\
\hline $\mathrm{I}-131$ & 8.0 days & beta ray/gamma ray & $606 \mathrm{keV} / 364 \mathrm{keV}$ & Diagnostic imaging (Gamma camera) Therapy \\
\hline Tc-99m & 6.0 hours & gamma ray & $140 \mathrm{keV}$ & Diagnostic imaging (Gamma camera) \\
\hline F-18 & 109.8 minutes & positron & $511 \mathrm{keV}$ & $\begin{array}{l}\text { Diagnostic imaging (PET) as a form of tetra- } \\
\text { fluoroborate }\end{array}$ \\
\hline Re-186 & 90.6 hours & beta ray/gamma ray & $1,070 \mathrm{keV} / 59 \mathrm{keV}$ & Therapy \\
\hline Re-188 & 17.0 hours & beta ray/gamma ray & $2,120 \mathrm{keV} / 155 \mathrm{keV}$ & Therapy \\
\hline At-211 & 7.2 hours & alpha ray/X-ray & $7,500 \mathrm{keV} / 77-92 \mathrm{keV}$ & Therapy \\
\hline
\end{tabular}

$\mathrm{T}_{1 / 2}$ : half-life, PET: positron emission tomography

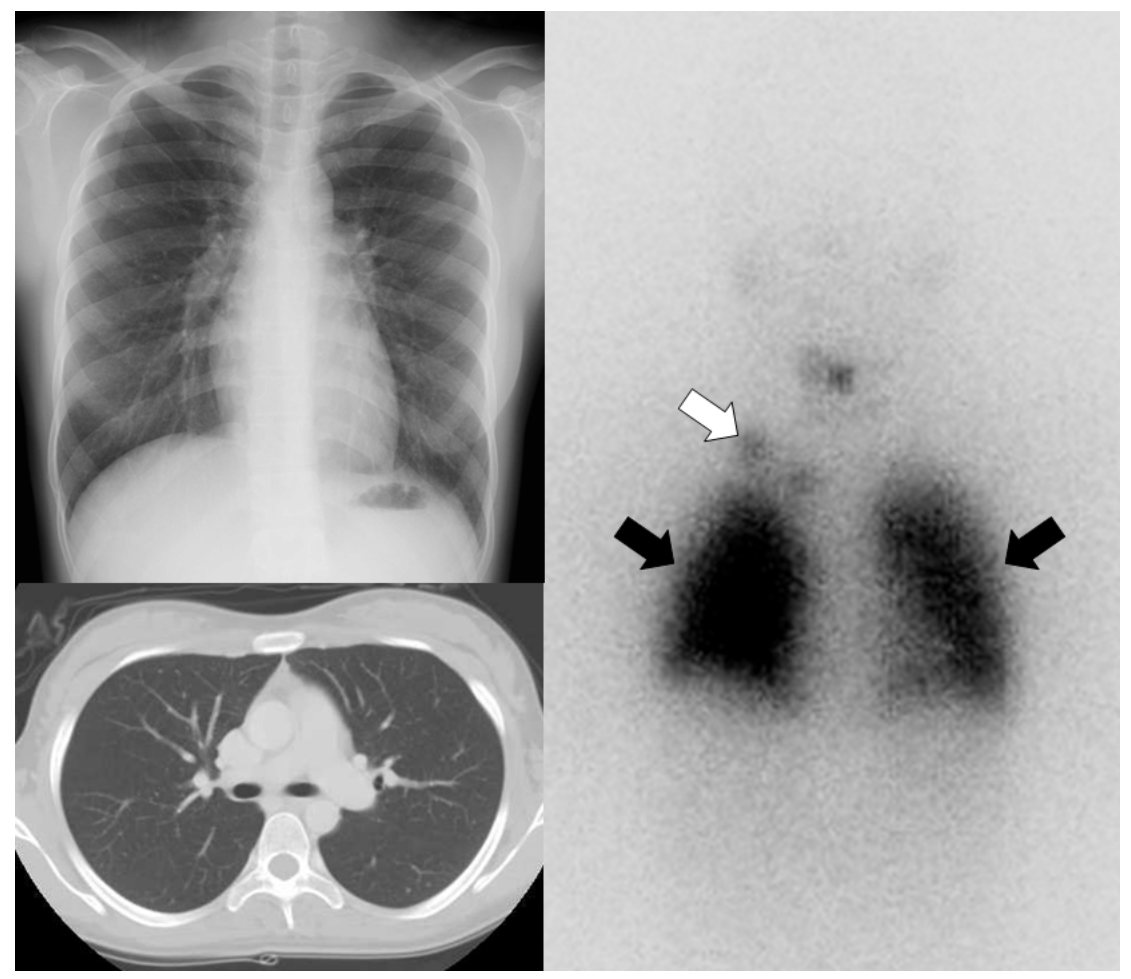

Figure 2. A 21-year-old female who underwent total thyroidectomy due to papillary thyroid cancer. Chest simple radiography and CT did not demonstrate any metastatic lesion of the cancer in the neck and chest regions. However, a radioiodine whole body scan revealed lymph node metastases (white arrow) in the right supraclavicular area and diffuse lung metastases (black arrows). 


\section{NIS and nuclear molecular imaging}

Molecular imaging, defined as the visual representation, characterization and quantification of biological processes at the cellular and subcellular levels within intact living organisms, can be obtained by various imaging technologies, such as optical imaging, nuclear imaging, magnetic resonance imaging (MRI), ultrasound imaging and computed tomography (CT) [28]. Molecular imaging has the potential to provide unique information that will guarantee the safety and efficacy of biotherapies which utilize antibodies, bacteria or cells in humans, and also will contribute to the future development of novel biotherapies [15].

With the emergence of cell therapies in regenerative medicine, it is important to track cells injected into subjects. In this context, NIS has been used in preclinical studies. With transfer of the NIS gene into therapeutic cells such as cytotoxic $\mathrm{T}$ or natural killer cells, nuclear molecular imaging modalities can image the cells with a relevant radiotracer, such as I-123, I-124, I-131, Tc-99m or F-18 TFB. The NIS-expressing cells have been imaged with planar scintigraphy, SPECT or PET according to the administered radio- tracers [15].

Nuclear imaging modalities, such as PET and SPECT, provide the 3-dimensional distribution of radiopharmaceuticals and have excellent sensitivity and high resolution with excellent tissue penetration depth [29]. These advantages permit these imaging techniques for use in translational research, from cell culture to preclinical animal models to clinical applications [28]. Both PET and SPECT give quantitative and non-invasive information on NIS gene expression or the number of NIS-expressing cells [15, 28].

As a gene reporter, NIS is able to be used for monitoring of gene and vector biodistribution and for trafficking of therapeutic cells $[6,15]$. Contrary to the diagnostic application of radioiodine nuclear imaging using NIS gene expression for the detection of thyroid cancer recurrence or metastases, NIS gene transfer is a prerequisite for radionuclide-based molecular imaging (Fig. 3). Non-invasive imaging of NIS expressing nonthyroidal cells with a gamma camera or PET upon viral gene transfer has been demonstrated feasible and safe in experimental animals and humans as well (Fig. 4) [6, 8].

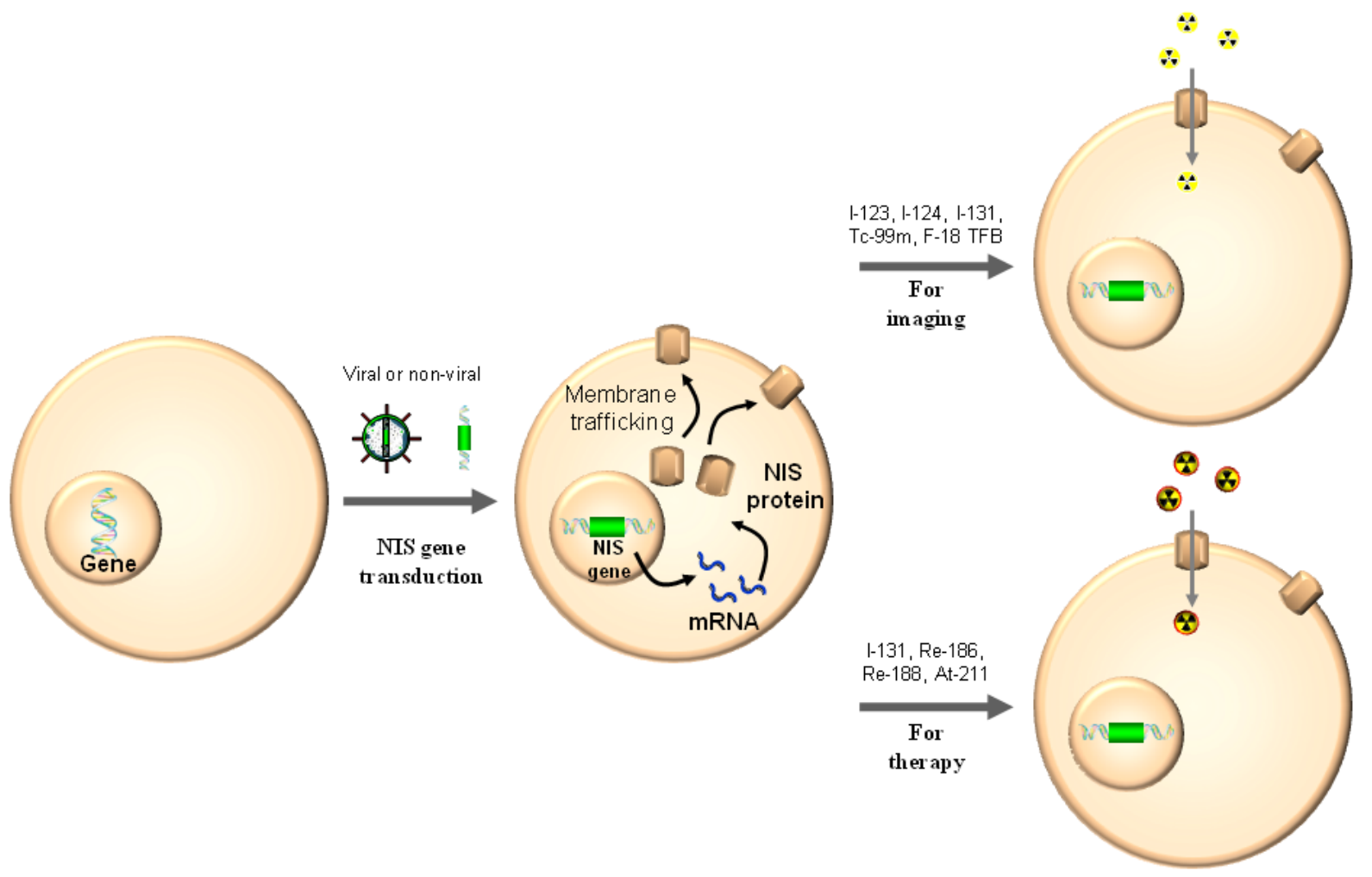

Figure 3. Cells without NIS gene expression obtain the function of iodine uptake with NIS gene transduction by viral or non-viral vector delivery. The cells can be imaged by radionuclide-based molecular imaging techniques using gamma ray or positron-emitting radiotracers and be cleared by beta or alpha particle-emitting radionuclides. 

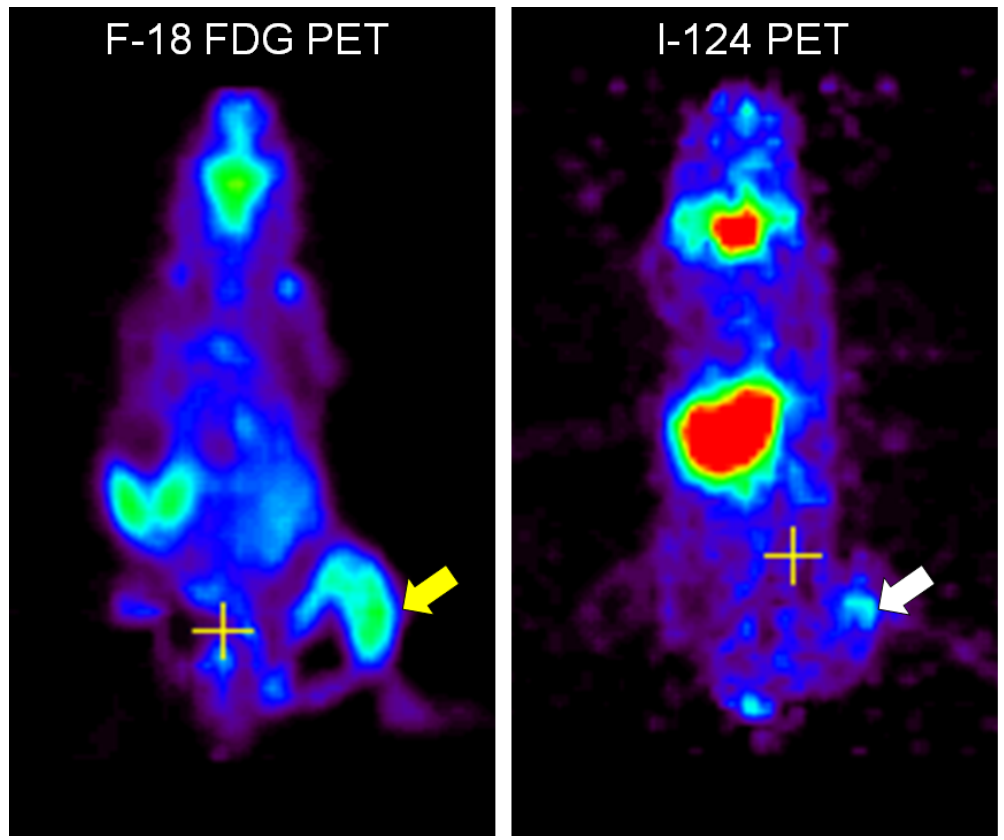

Figure 4. Visualization of macrophages expressing NIS with radionuclide-based molecular imaging. Inflammation at the right thigh (yellow arrow) was well visualized in F-18 FDG microPET imaging. Migration of microphages expressing NIS to the inflammation site (white arrow) was clearly visualized on I- 124 microPET imaging [7].
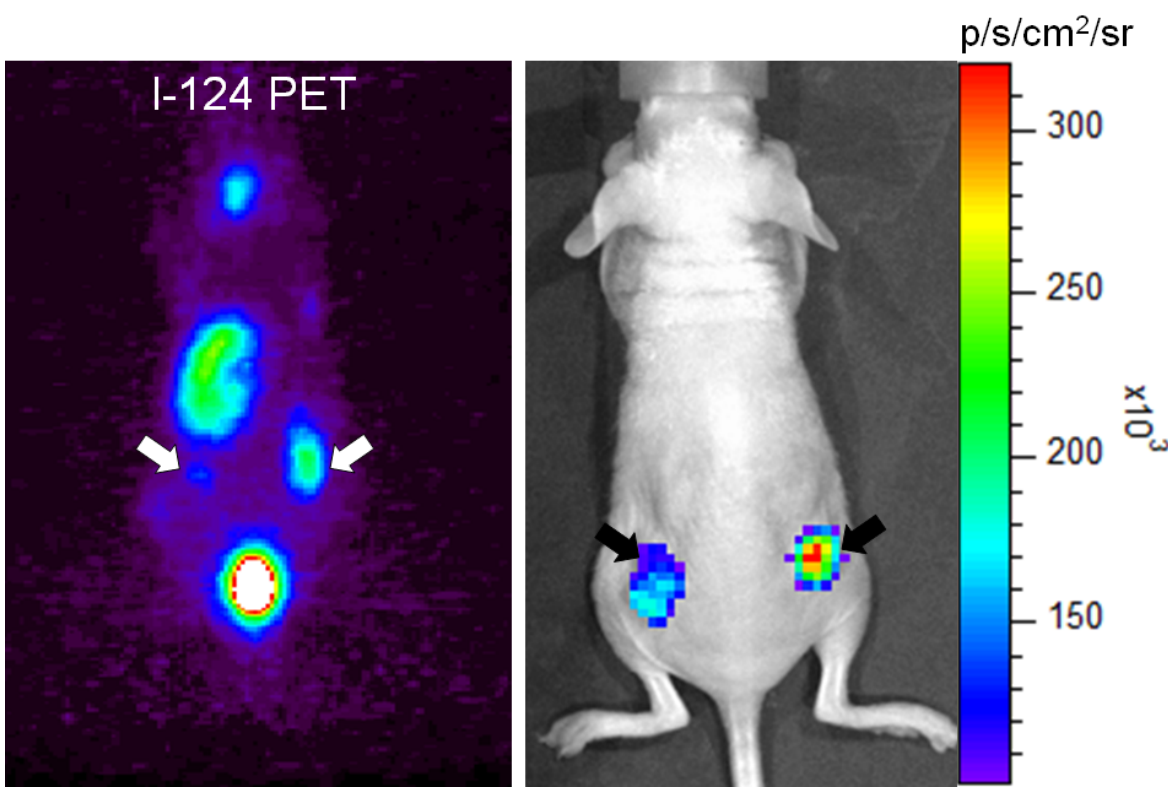

Figure 5. Visualization of tumor cells expressing NIS with optical molecular imaging using I- 124 . Tumor xenografts of anaplastic thyroid cancer cells expressing NIS were well visualized on both microPET imaging (white arrows) and Cerenkov luminescence imaging (black arrows) after intravenous administration of I-I 24 [I7].

Recently, I-131 and I-124, which are commonly used for thyroid imaging, were reported to have sufficient energy to result in Cerenkov radiation that can be visualized with sensitive optical imaging equipment and cells transfected with NIS gene were successfully imaged with the radioiodines using an optical imaging instrument in an in vivo animal model (Fig. 5) [17].
Radioiodine accumulation in NIS-expressing organs such as the thyroid is a deterrent to scintigraphic visualization of NIS-expressing cells in various animal models. To remove radioiodine uptake in the thyroid gland and better visualize NIS-expressing cells, the animal can be prepared with surgical total thyroidectomy or radioiodine ablation before administration of the NIS-expressing cells [30]. 


\section{Use of NIS for therapeutic purposes in clini- cal nuclear medicine}

Molecular radionuclide-based therapy of differentiated NIS-expressing thyroid cancer with I-131 was the cornerstone on which nuclear medicine was built and it has been a very successful example of targeted therapy to reduce recurrence and mortality for almost 70 years (Fig. 6) [31, 32]. Therapeutic application of I-131 for hyperthyroidism and thyroid cancer was implemented in the early 1940s, and success of the applications resulted in the approval of medical radioisotope use and initiation of atomic medicine, later re-named nuclear medicine [31, 33].

Radioiodine therapy for thyroid diseases relies on the fact that thyroid follicular cells and differentiated thyroid cancer are efficient at trapping circulating radioiodine than other tissues [25]. I-131 treatment has been the most preferred therapeutic modality by physicians for hyperthyroidism in the United States and it has been one of the key treatment modalities for differentiated thyroid cancers worldwide [34, 35]. However, I-131 treatment is not very effective in de-differentiated thyroid cancer, which down-regulates NIS expression, and is meaningless in anaplastic thyroid and medullary thyroid cancers, which do not express NIS. One possible treatment option for de-differentiated thyroid cancer is the induction of re-differentiation with differentiating agents such as retinoic acid and thiazolidinedione [31, 36].

Expression of NIS is not uncommon in breast and stomach cancers, and some reports have shown visualization of primary or metastatic lesions of such cancers with radioiodine or Tc- $99 \mathrm{~m}$ scintigraphy [37-40]. The possibility of radioiodine treatment for cancers with sufficient NIS expression has been suggested; however, as far as the author knows, clinical reports on such treatment with successful outcome have yet to be published, likely due to insufficient NIS expression [16].

Although it has not been clinically attempted, anaplastic or medullary thyroid cancers lacking NIS expression can be treated with I-131 after NIS gene transfer to the tumors. Additionally, other tumor entities which do not express NIS can also be treated with the same strategy [31].
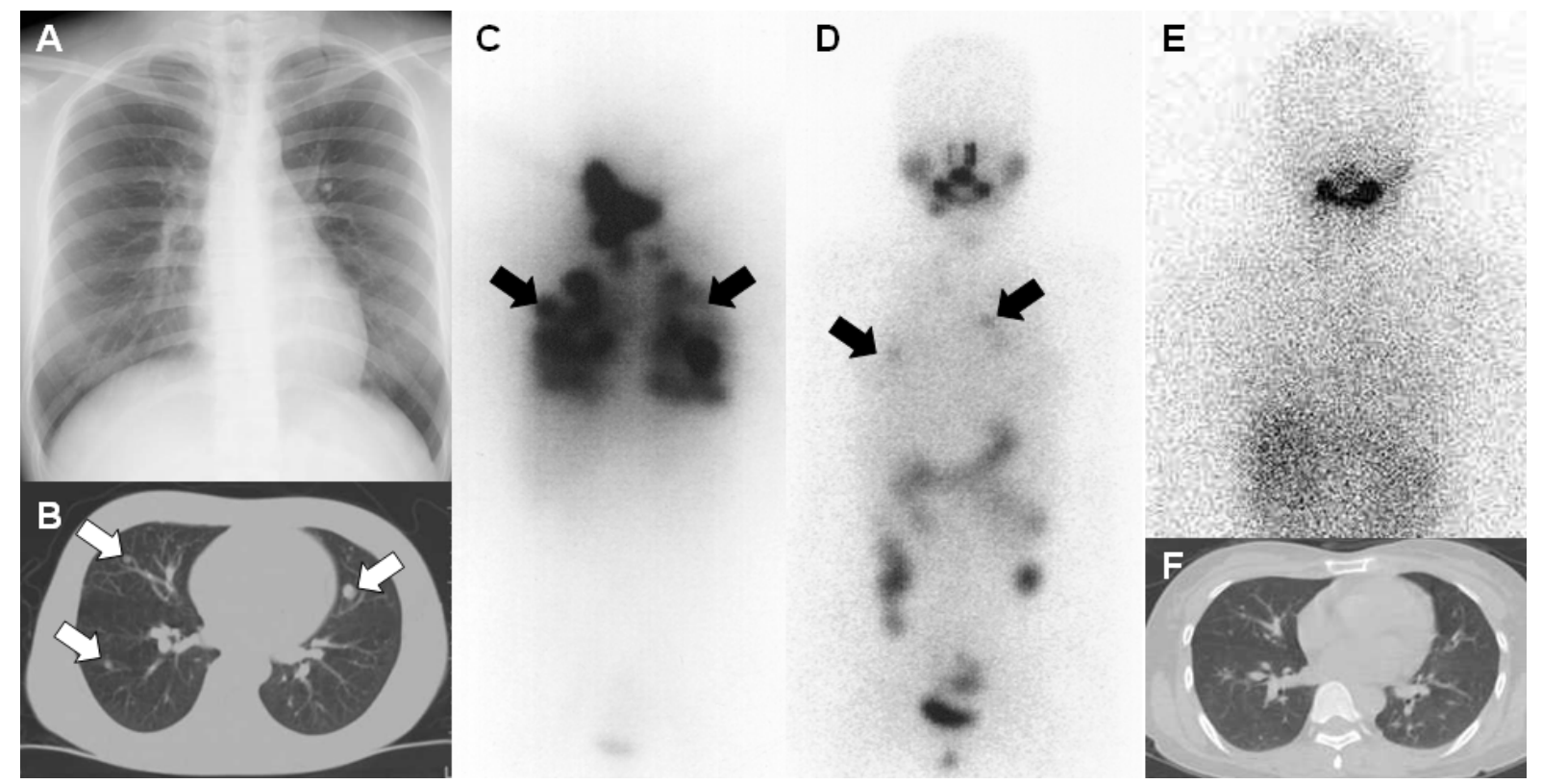

Figure 6. A 26-year-old female who underwent total thyroidectomy due to papillary thyroid cancer. (A) Chest simple radiograph did not demonstrate any observable metastatic lesions of the cancer. (B) CT scan of the chest demonstrated several metastatic lesions of the cancer in both lung fields (white arrows). TSH-stimulated serum thyroglobulin was $65.0 \mathrm{ng} / \mathrm{mL}$. The patient was diagnosed with metastatic thyroid cancer of the lung. (C) A post initial high dose I-I $3 \mathrm{I}$ treatment (I $50 \mathrm{mCi}$ ) scan revealed numerous metastatic lung lesions. (D) A post $2^{\text {nd }}$ high dose $\mathrm{I}-\mathrm{I} 3 \mathrm{I}$ treatment $(200 \mathrm{mCi})$ scan revealed fewer but still several metastatic lung lesions (black arrows). (E, F) A post $3^{\text {rd }}$ high dose $\mathrm{I}-\mathrm{I} 3 \mathrm{I}$ treatment $(200 \mathrm{mCi})$ scan revealed no remarkable radioiodine uptake in both lung fields and chest CT showed only tiny lung nodules having no clinical significance. TSH-stimulated serum thyroglobulin was $1.4 \mathrm{ng} / \mathrm{mL}$ after the third treatment. The patient had achieved complete remission with three times of high dose I-I $3 \mathrm{I}$ treatment and her status still remains disease-free at 7 years follow-up. 


\section{NIS and radionuclide gene therapy}

In addition to its imaging potential, NIS can be used as a therapeutic gene through its ability to concentrate therapeutic doses of radionuclides in target cells [15]. Contrary to the therapeutic application of I-131 using NIS gene expression for treating thyroid cancer recurrence or metastases, NIS gene transfer is a prerequisite for tumors without NIS gene expression. After the transfer of the NIS gene into various cancer cells, they can be treated with beta or alpha particle-emitting radionuclides including I-131, Re-186, Re-188 and At-211, which are accumulated via NIS (Fig. 3) [31].

Right after NIS was cloned by Carrasco et al. in 1996, many researchers started to use the gene for therapeutic purposes with I-131, and in general, the results were effective. The effect of I-131 NIS gene therapy was enhanced with higher doses of I-131 and intervention with retinoic acid or dexamethasone, which increase radioiodine uptake [41]. Transcription factors such as Pax-8 and TTF-1 could induce or promote iodide uptake and specifically prolong iodide retention time in cancer cells [42, 43].

Re-188 and At-211 were also used as therapeutic radionuclides with NIS gene therapy to nonthyroidal tumors. Re-188 has advantages over I-131, as its beta ray energy is higher and has a shorter half-life, which makes it a more suitable radionuclide for NIS-expressing tumors. In addition, it is conveniently obtained from a W-188/Re-188 generator [44]. At-211, which emits extremely cytotoxic alpha-particles, is known to be taken up by NIS in thyroid tissue and has been used as a therapeutic radionuclide for NIS-expressing tumors in cell culture and animal experiments [21, 45, 46]. In addition to very effective tumoricidal effects, At-211 has the advantages of alpha-particle's short range and a short half-life, which allow for a minimal radiation burden to the surrounding environment, including people [46].

However, single radionuclide NIS gene therapy might have limited therapeutic effects and can produce serious adverse effects positively related to the amount of administered radionuclide dose. Reducing the radionuclide dose for NIS gene therapy is able to reduce the adverse effects, but might lead to limited effectiveness [47]. Combined treatment of radionuclide NIS gene therapy with other therapeutic approaches could be more efficient to improve therapeutic outcomes and can reduce adverse effects of radionuclide NIS gene therapy by reducing the radionuclide dose. Chemotherapy, genciclovir HSV-tk gene therapy, immunotherapy, external beam radiotherapy and siRNA therapy have been combined with radionuclide NIS gene therapy, and the results were almost always successful [8-10, 47].

Even though radionuclide NIS gene therapy has been shown to be effective in in vivo animal models, several issues must be resolved before this novel strategy can be useful clinically. First of all, vector systems having safe, effective and specific NIS gene delivery to the tumor are needed. The optimal time interval between NIS gene transfer and therapeutic radionuclide administration should be determined to obtain the most effective therapeutic results. Organs that normally express NIS, such as the thyroid gland and the salivary glands, are inevitably damaged by the therapeutic radionuclide; therefore, protecting or managing strategies for the organs need to be developed [13, 31, 48].

Even though radionuclide NIS gene therapy is only performed in the preclinical setting at the moment, clinical trials of the treatment are likely to happen in the not-too-distant future with advances in efficiency and safety of the therapy by close communication between these basic biological studies and clinical experiences of thyroid cancer treatment with I-131.

\section{NIS-based molecular imaging and radionu- clide gene therapy; limitations and future directions}

NIS provides an advantage of both as reporter and therapeutic genes and therefore, NIS gene transfer makes it possible to image, monitor and treat the tumor with appropriate radionuclides, just as in differentiated thyroid cancer. Another advantage of NIS is wide availability of appropriate diagnostic and therapeutic radiopharmaceuticals. Although NIS is one of the best theranostic genes, there are several pending questions that must be answered before its clinical use.

Tissues that normally express endogenous NIS such as the thyroid gland, salivary glands and stomach, are an obstacle for NIS-based imaging or treatment. Uptake of imaging radiotracers to the tissues conceals trafficking target cells expressing NIS which are located near the tissues. Uptake of therapeutic radionuclides to the normal tissues can damage the organs and may reduce tracer uptake to the target cells expressing exogenous NIS.

Retention time of radioiodine is generally short in NIS-transduced cells by rapid washout of the radioiodine, therefore absorbed dose and toxicity to the target cells might be limited and it precludes successful radioiodine NIS gene therapy. To prolong the retention time, drugs such as lithium carbonate, or 
co-transfer of the thyroid peroxidase gene was introduced, however, results were conflicting and not very effective [13]. Co-transfer of the thyroglobulin gene was also suggested to increase retention time [42]. Efflux of iodine from the cell is known to be related to pendrin, SLC5A8 and ClCn5, and even though not verified by experiments, down-regulation of these proteins can delay iodine efflux from the cell [42]. Ablation of the thyroid gland and low iodine diet are able to prolong the retention time in NIS transduced tumor cells, however applicability of this strategy is limited in a clinical situation. It can be feasibly applied only in thyroid cancer patients receiving previous thyroidectomy. Enhancement of radioiodine uptake by up-regulation of NIS expression has been tried with drugs such as retinoic acid or dexamethasone, troglitazone and external radiation [49, 50]. Histone deacetylase inhibitors (e.g. depsipeptide, trichosatin A and valproic acid) and demethylating agents (5-azacytidine) have been used to restore endogenous NIS expression [1]. In addition to increasing radiation dose to the NIS expressing cells, radiosensitization can enhance the biological effect of the same radiation dose. DNA damage repair inhibitors revealed a therapeutic benefit with radionuclide NIS gene therapy [51]. Further studies are needed for validation and optimization of the pharmacological approaches for prolonging the retention time, delaying iodine efflux, restoring/up-regulation of NIS expression and enhancing radiosensitization before practical use.

Several new diagnostic or therapeutic radiopharmaceuticals for NIS were recently studied. Cells expressing NIS can be imaged with F-18 FTB PET instead of radioiodine scintigraphy and be treated more effectively with Re-188, Re-186 or At-211 instead of I-131. Some of the radiopharmaceuticals are not suitable at present due to scarce availability and nontrivial safety issues related to their production and handling. Technical advancement of the production and handling skills for the radiopharmaceuticals is warranted.

With administration of I-131, the thyroid gland takes up I-131 and retains it within the gland for a long time by organification of the radioiodine. This will end in permanent hypothyroidism by radioablation of normal thyroid tissue. The salivary gland also accumulates the radionuclide and xerostomia can occur by radiation sialoadenitis related to uptake of the radionuclide. To maintain sufficient radioiodine uptake to the extrathyroidal cancer tissues expressing NIS, uptake of radioiodine to the thyroid gland can be suppressed by thyroid hormone replacement and antithyroidal drugs [52]. Stable iodine administration before administration of radioiodine can reduce radi- oiodine to the gland as well [13]. Radioiodine uptake in the salivary gland can be expelled by manual massage of the gland and may reduce incidence of xerostomia related to radiation-induced sialoadenitis [53]. Strategies for preventing or reducing side effects to normal tissues expressing NIS by radionuclides uptake must be developed and optimized before common clinical application of NIS-based radionuclide theranostics.

\section{Conclusions}

Although diagnostic and therapeutic use of the NIS gene began in clinics more than half a century ago, understanding of the biology of NIS has been advancing rapidly the last two decades. NIS-based molecular imaging and radionuclide gene therapy, cutting edge technologies in molecular imaging and gene therapy arenas, were born with imitation of diagnostic and therapeutic applications in the field of clinical thyroid practice. With fast advancement of molecular imaging and gene therapy with active research, these bench technologies are likely to be used in the clinical setting in the near future.

\section{Acknowledgements}

This study was supported by a grant (A102132) of the Korea Health Technology R\&D Project, Ministry of Health \& Welfare, Republic of Korea and the Ministry of Knowledge Economy (MKE), and a grant of the Korea Institute for Advancement of Technology (KIAT) and Daegyeong Leading Industry Office through the Leading Industry Development for Economic Region.

\section{Competing Interests}

The authors have declared that no competing interest exists.

\section{References}

1. Riesco-Eizaguirre G, Santisteban P. A perspective view of sodium iodide symporter research and its clinical implications. Eur J Endocrinol. 2006; 155: 495-512.

2. Soto GD, Halperin I, Squarcia M, Lomena F, Domingo MP. Update in thyroid imaging. The expanding world of thyroid imaging and its translation to clinical practice. Hormones (Athens). 2010; 9: 287-98.

3. Verburg FA, de Keizer B, van Isselt JW. Use of radiopharmaceuticals for diagnosis, treatment, and follow-up of differentiated thyroid carcinoma. Anticancer Agents Med Chem. 2007; 7: 399-409.

4. Dai G, Levy O, Carrasco N. Cloning and characterization of the thyroid iodide transporter. Nature. 1996; 379: 458-60.

5. Msaouel P, Dispenzieri A, Galanis E. Clinical testing of engineered oncolytic measles virus strains in the treatment of cancer: an overview. Curr Opin Mol Ther. 2009; 11: 43-53.

6. Barton KN, Stricker H, Brown SL, Elshaikh M, Aref I, Lu M, et al. Phase I study of noninvasive imaging of 
adenovirus-mediated gene expression in the human prostate. Mol Ther. 2008; 16: 1761-9.

7. Seo JH, Jeon YH, Lee YJ, Yoon GS, Won DI, Ha JH, et al. Trafficking macrophage migration using reporter gene imaging with human sodium iodide symporter in animal models of inflammation. J Nucl Med. 2010; 51: 1637-43.

8. Ahn SJ, Jeon YH, Lee YJ, Lee YL, Lee SW, Ahn BC, et al. Enhanced anti-tumor effects of combined MDR1 RNA interference and human sodium/iodide symporter (NIS) radioiodine gene therapy using an adenoviral system in a colon cancer model. Cancer Gene Ther. 2010; 17: 492-500.

9. Jeon YH, Ahn SJ, Lee YJ, Lee YL, Lee SW, Park SY, et al. Human sodium iodide symporter added to multidrug resistance 1 small hairpin RNA in a single gene construct enhances the therapeutic effects of radioiodine in a nude mouse model of multidrug resistant colon cancer. Cancer Biother Radiopharm. 2011; 25: 671-9.

10. Lee YL, Lee YJ, Ahn SJ, Choi TH, Moon BS, Cheon GJ, et al. Combined radionuclide-chemotherapy and in vivo imaging of hepatocellular carcinoma cells after transfection of a triple-gene construct, NIS, HSV1-sr39tk, and EGFP. Cancer Lett. 2010; 290: 129-38.

11. Spitzweg C, Harrington KJ, Pinke LA, Vile RG, Morris JC. Clinical review 132: The sodium iodide symporter and its potential role in cancer therapy. J Clin Endocrinol Metab. 2001; 86: 3327-35.

12. Dohan O, De la Vieja A, Paroder V, Riedel C, Artani M, Reed M, et al. The sodium/iodide Symporter (NIS): characterization, regulation, and medical significance. Endocr Rev. 2003; 24: 48-77.

13. Hingorani M, Spitzweg C, Vassaux G, Newbold K, Melcher A, Pandha $\mathrm{H}$, et al. The biology of the sodium iodide symporter and its potential for targeted gene delivery. Curr Cancer Drug Targets. 2010; 10: 242-67.

14. Wapnir IL, van de Rijn M, Nowels K, Amenta PS, Walton K, Montgomery $\mathrm{K}$, et al. Immunohistochemical profile of the sodium/iodide symporter in thyroid, breast, and other carcinomas using high density tissue microarrays and conventional sections. J Clin Endocrinol Metab. 2003; 88: 1880-8.

15. Baril P, Martin-Duque P, Vassaux G. Visualization of gene expression in the live subject using the $\mathrm{Na} / \mathrm{I}$ symporter as a reporter gene: applications in biotherapy. Br J Pharmacol. 2010; 159: 761-71.

16. Chung JK. Sodium iodide symporter: its role in nuclear medicine. J Nucl Med. 2002; 43: 1188-200.

17. Jeong SY, Hwang MH, Kim JE, Kang S, Park JC, Yoo J, et al. Combined Cerenkov luminescence and nuclear imaging of radioiodine in the thyroid gland and thyroid cancer cells expressing sodium iodide symporter: initial feasibility study. Endocr J. 2011; 58: 575-83.

18. Silberstein EB, Alavi A, Balon HR, Becker DV, Brill DR, Clarke SEM, et al. Society of Nuclear Medicine Procedure Guideline for Therapy of Thyroid Disease with Iodine-131 (Sodium Iodide) Version 2.0. Society of Nuclear Medicine. 2005.

19. Rault E, Vandenberghe S, Van Holen R, De Beenhouwer J, Staelens S, Lemahieu I. Comparison of image quality of different iodine isotopes (I-123, I-124, and I-131). Cancer Biother Radiopharm. 2007; 22: 423-30.

20. Jauregui-Osoro M, Sunassee K, Weeks AJ, Berry DJ, Paul RL, Cleij $\mathrm{M}$, et al. Synthesis and biological evaluation of [(18)F]tetrafluoroborate: a PET imaging agent for thyroid disease and reporter gene imaging of the sodium/iodide symporter. Eur J Nucl Med Mol Imaging. 2010; 37: 2108-16.

21. Lindencrona U, Forssell-Aronsson E, Nilsson M. Transport of free 211At and 125I- in thyroid epithelial cells: effects of anion channel blocker 4,4'-diisothiocyanostilbene-2,2'-disulfonic acid on apical efflux and cellular retention. Nucl Med Biol. 2007; 34 : 523-30.

22. Frier M. Rhenium-188 and copper-67 radiopharmaceuticals for the treatment of bladder cancer. Mini Rev Med Chem. 2004; 4: 61-8.

23. Jansen DR, Krijger GC, Kolar ZI, Zonnenberg BA, Zeevaart JR. Targeted radiotherapy of bone malignancies. Curr Drug Discov Technol. 2010; 7: 233-46.

24. Imam SK. Advancements in cancer therapy with alpha-emitters: a review. Int J Radiat Oncol Biol Phys. 2001; 51: 271-8.

25. Ahn BC, Lee SW, Lee J, Kim C. Pulmonary aspergilloma mimicking metastasis from papillary thyroid cancer. Thyroid. 2011; 21: 555-8

26. Johnson NA, LeBeau SO, Tublin ME. Imaging surveillance of differentiated thyroid cancer. Radiol Clin North Am. 2011; 49: 473-87.

27. Wong KK, Zarzhevsky N, Cahill JM, Frey KA, Avram AM. Hybrid SPECT-CT and PET-CT imaging of differentiated thyroid carcinoma. Br J Radiol. 2009; 82: 860-76.

28. Ahn BC. Applications of molecular imaging in drug discovery and development process. Curr Pharm Biotechnol. 2011; 12: 459-68.

29. Pichler BJ, Wehrl HF, Judenhofer MS. Latest advances in molecular imaging instrumentation. J Nucl Med. 2008; 49 Suppl 2: 5S-23S.

30. Shim HK, Kim SG, Kim TS, Kim SK, Lee SJ. Total thyroidectomy in the mouse: the feasibility study in the non-thyroidal tumor model expressing human sodium/Iodide symporter gene. Nucl Med Mol Imag. 2011; 45: 103-10.

31. Verburg FA, Brans B, Mottaghy F. Molecular nuclear therapies for thyroid carcinoma. Methods. 2011.

32. Mazzaferri EL, Kloos RT. Clinical review 128: Current approaches to primary therapy for papillary and follicular thyroid cancer. J Clin Endocrinol Metab. 2001; 86: 1447-63.

33. Seidlin SM, Marinelli LD, Oshry E. Radioactive iodine therapy; effect on functioning metastases of adenocarcinoma of the thyroid. J Am Med Assoc. 1946; 132: 838-47.

34. Cooper DS, Doherty GM, Haugen BR, Kloos RT, Lee SL, Mandel SJ, et al. Revised American Thyroid Association management guidelines for patients with thyroid nodules and differentiated thyroid cancer. Thyroid. 2009; 19: 1167-214.

35. Bahn Chair RS, Burch HB, Cooper DS, Garber JR, Greenlee MC, Klein I, et al. Hyperthyroidism and other causes of thyrotoxicosis: management guidelines of the American Thyroid Association and American Association of Clinical Endocrinologists. Thyroid. 2011; 21: 593-646.

36. Oh SW, Moon SH, Park do J, Cho BY, Jung KC, Lee DS, et al. Combined therapy with (131)I and retinoic acid in Korean patients with radioiodine-refractory papillary thyroid cancer. Eur J Nucl Med Mol Imaging. 2011; 38: 1798-805.

37. Wu SY, Kollin J, Coodley E, Lockyer T, Lyons KP, Moran E, et al. I-131 total-body scan: localization of disseminated gastric adenocarcinoma. Case report and survey of the literature. J Nucl Med. 1984; 25: 1204-9.

38. Tazebay UH, Wapnir IL, Levy O, Dohan O, Zuckier LS, Zhao $\mathrm{QH}$, et al. The mammary gland iodide transporter is expressed during lactation and in breast cancer. Nat Med. 2000; 6: 871-8.

39. Spitzweg C, Morris JC. The sodium iodide symporter: its pathophysiological and therapeutic implications. Clin Endocrinol (Oxf). 2002; 57: 559-74.

40. Moon DH, Lee SJ, Park KY, Park KK, Ahn SH, Pai MS, et al. Correlation between $99 \mathrm{mTc}$-pertechnetate uptakes and expressions of human sodium iodide symporter gene in breast tumor tissues. Nucl Med Biol. 2001; 28: 829-34.

41. Willhauck MJ, DJ OK, Wunderlich N, Goke B, Spitzweg C. Stimulation of retinoic acid-induced functional sodium iodide 
symporter (NIS) expression and cytotoxicity of (1)(3)(1)I by carbamazepine in breast cancer cells. Breast Cancer Res Treat. 2011; 125: 377-86.

42. Mu D, Huang R, Ma X, Li S, Kuang A. Radioiodine therapy of thyroid carcinoma following Pax- 8 gene transfer. Gene Ther. 2011; doi:gt2011110 [pii] 10.1038/gt.2011.110.

43. Altmann A, Schulz RB, Glensch G, Eskerski H, Zitzmann S, Eisenhut $M$, et al. Effects of Pax8 and TTF-1 thyroid transcription factor gene transfer in hepatoma cells: imaging of functional protein-protein interaction and iodide uptake. J Nucl Med. 2005; 46: 831-9.

44. Lee YJ, Chung JK, Kang JH, Jeong JM, Lee DS, Lee MC. Wild-type p53 enhances the cytotoxic effect of radionuclide gene therapy using sodium iodide symporter in a murine anaplastic thyroid cancer model. Eur J Nucl Med Mol Imaging. 2010; 37: 235-41.

45. Lindencrona U, Nilsson M, Forssell-Aronsson E. Similarities and differences between free 211At and 125I- transport in porcine thyroid epithelial cells cultured in bicameral chambers. Nucl Med Biol. 2001; 28: 41-50.

46. Petrich T, Quintanilla-Martinez L, Korkmaz Z, Samson E, Helmeke HJ, Meyer GJ, et al. Effective cancer therapy with the alpha-particle emitter [211At]astatine in a mouse model of genetically modified sodium/iodide symporter-expressing tumors. Clin Cancer Res. 2006; 12: 1342-8.

47. Kim J, Ahn BC, Hwang MH, Lee HW, Jeon YH, Jeong SY, et al. Combined RNA Interference of Hexokinase II and I-131 human Sodium Iodide Symporter Gene Therapy in Anaplastic Thyroid Carcinoma. J Nucl Med. 2011; 52: 1756-63.

48. Scanlon KJ. Cancer gene therapy: challenges and opportunities. Anticancer Res. 2004; 24: 501-4.

49. Spitzweg C, Scholz IV, Bergert ER, Tindall DJ, Young CY, Goke $\mathrm{B}$, et al. Retinoic acid-induced stimulation of sodium iodide symporter expression and cytotoxicity of radioiodine in prostate cancer cells. Endocrinology. 2003; 144: 3423-32.

50. Harrington KJ, Melcher A, Vassaux G, Pandha HS, Vile RG. Exploiting synergies between radiation and oncolytic viruses. Curr Opin Mol Ther. 2008; 10: 362-70.

51. Hingorani M, White CL, Zaidi S, Pandha HS, Melcher AA, Bhide SA, et al. Therapeutic effect of sodium iodide symporter gene therapy combined with external beam radiotherapy and targeted drugs that inhibit DNA repair. Mol Ther. 2010; 18: 1599-605.

52. Wapnir IL, Goris M, Yudd A, Dohan O, Adelman D, Nowels K, et al. The $\mathrm{Na}+$ /I- symporter mediates iodide uptake in breast cancer metastases and can be selectively down-regulated in the thyroid. Clin Cancer Res. 2004; 10: 4294-302.

53. Kim HW, Ahn BC, Lee SW, Lee J. Effect of Parotid Gland Massage on Parotid Gland Tc-99m pertechnetate Uptake. Thyroid. 2012; doi:10.1089/thy.2011-0188. 